\title{
Analysis of the Prescription of Antibiotics During the Implementation of COVID-19 Personal Protection Measures in a Regional Health System
}

\section{Paula Rojas-Garcia (D) Fernando Antoñanzas (D)}

Department of Economics and Business, University of La Rioja, Logroño, La Rioja, Spain
Correspondence: Paula Rojas-Garcia Department of Economics and Business, University of La Rioja, Logroño, La Rioja, Spain

Email paula.rojas@unirioja.es
Introduction: The rational consumption of antibiotics is a valuable goal for developed countries. Antibiotic resistance (AMR) was the main health threat before the coronavirus-19 (COVID-19) pandemic. To restrict COVID-19 transmission, the Spanish government implemented personal protection measures, including the decree of a lockdown. The objective of this study is to analyze the prescription of antibiotics during the implementation of COVID19 personal protection measures in primary care in a Spanish region.

Materials and Methods: Primary monthly official dispensations of antibacterials for systemic use (J01) were analyzed, disaggregating by clinical (active principle, age and sex of the patient) and socio-economic variables (basic health zone and level of income). Defined daily doses per thousand inhabitants (DID) prescribed in 2020 were compared with the prescription in 2019 using Chi-square test.

Results: In 2020, the prescription of antibiotics (11.37 DID) was significantly lower $(-23.73 \%)$ than in 2019 (14.91 DID). The main reduction in the amount prescribed was found in May $(-42.64 \%)$. However, the prescription was significantly higher $(71.34 \%)$ in February 2020 than in the same month in 2019 in nursing homes. In March 2020, prescriptions were lower $(-13.71 \%)$ than in the same month in 2019 , except for the middle-income group, in which prescriptions were higher $(9.67 \%)$, as well as azithromycin $(10.11 \%)$. In April and May 2020, prescriptions were significantly lower than in 2019 in all age groups and both in women and men.

Conclusion: Personal protection measures against COVID-19 transmission (lockdown, mask, social distance and increased hygiene) coincide in time with the greatest reduction in antibiotic prescription.

Keywords: antibiotics, COVID-19, personal protection measures, co-payment

\section{Introduction}

Since the first informed case of coronavirus-19 (COVID-19) in December 2019, no drug has been proven to be effective. ${ }^{1}$ It was not until May 2020 that the antiviral drug remdesivir was reported to shorten recovery time and decrease mortality. ${ }^{2}$ In the meantime, the antibiotic azithromycin with hydroxychloroquine was used as a firstline treatment against COVID-19, due to past successful performance in other viral epidemics. ${ }^{3}$ However, no evidence of the effectiveness of this treatment was found, ${ }^{4}$ which could lead to unnecessary antibiotic consumption and increased antibiotic resistance (AMR), ${ }^{5}$ the main health threat faced by the World Health Organization (WHO) before the COVID-19 pandemic. ${ }^{6}$ The latest data from the European Centre 
for Disease prevention and Control (ECDC) show that in 2019, Spain ranked 5th in Europe for antibiotic consumption at community level and 14th in hospitals. In Spain, around 3,000 people die every year due to a resistant infection, which is mainly caused by the inappropriate use of antibiotics. $^{7}$

Based on the WHO's recommendation that governments should issue "stay-at-home" orders to evade further transmission, ${ }^{8}$ the Spanish government decreed a lockdown on the 15th of March until the 1st of May, when the population was allowed to go outside during certain hours of the day. ${ }^{9}$ Also, strict personal protection measures were implemented, such as having to wear a mask or maintain interpersonal distance. ${ }^{10}$ Furthermore, health systems implemented rapid tests to improve the detection capacity. ${ }^{11-14}$ Some authors have suggested that the previous restrictive measures could have also blocked the transmission of other communityacquired infections, with their corresponding effect on the use of antibiotics. ${ }^{15}$

In the fight against the COVID-19 pandemic, the availability of information at a regional level and with an adequate level of disaggregation and detail is essential. ${ }^{11}$ The objective of this study is to analyze the prescription of antibiotics during the implementation of COVID-19 protection measures in primary care in a Spanish region. The analysis is performed considering clinical variables (active principle, age and sex of the patient) and socio-economic variables (Basic Health Zone, BHZ, and co-payment rate determined by level of income).

\section{Materials and Methods}

The analysis was performed with the database of primary monthly official dispensations of subgroup J01 antibacterials for systemic use of the Anatomical Therapeutic Chemical (ATC). ${ }^{16}$ The Department of Pharmaceutical and Health Products of La Rioja provided the primary monthly data from January 2019 to December 2020 including date of dispensation (month and year), active principle prescribed, number of packages, total expenses (retail price) and patient's level of income (following the Royal Decree Law 16/2012, ${ }^{17}$ which established the individual health classification TSI).

La Rioja is an Autonomous Community of Spain with a population of 316,137 inhabitants as of July $2020 ;^{18}$ its public health service has a budget of 1,455 euros per capita (year 2020). ${ }^{19}$ The antibiotic prescription was expressed in defined daily doses per thousand inhabitants (DID). The total prescription was also expressed in number of recipes, packs and expenditure in euro. Analyzes were disaggregated by active principle, Basic Health Zone, age group and sex, and level of income. The results section follows this same disaggregation scheme.

By active principle, a distinction is made between antibacterial for systemic use (J01); amoxicillin and betalactamase inhibitor (J01CR02); amoxicillin (J01CA04); cefuroxime (J01DC02); azithromycin (J01FA10); doxycycline (J01AA02); and levofloxacin (J01MA12).

The population was studied by BHZ. La Rioja is divided into twenty $\mathrm{BHZ}$, which are groups of patients clustered by regional distance. Eight BHZs are located in an urban area and the rest in a rural area. Nursing homes in La Rioja form a single BHZ since it is a group of patients with specific health needs. ${ }^{20}$

Also, the population was studied by sex and age groups, from 15 to 89 years because the DID is established for adult consumption, following the WHO methodology, which is the assumed average maintenance dose per day for a drug used as its main indication in adults. ${ }^{21}$ In Spain, there is an administrative classification for healthcare in the sense that people up to 14 years are considered children, hence eligible for pediatric care, and over 15 years they are treated as adults. ${ }^{22}$ Therefore, in this study prescriptions follow this classification.

The Royal Decree Law 16/2012 ${ }^{17}$ established an individual classification based on income level, which would determine the pharmaceutical co-payment percentage. Pensioners with income below $€ 100,000$ form group TSI 002 and they have a pharmaceutical co-payment of $10 \%$, with monthly limits of $€ 8$ (if income below $€ 18,000$ ) or $€ 18$ (if income between $€ 18,000$ and $€ 100,000$ ). Workers with income below $€ 18,000$ form group TSI 003 and they have a pharmaceutical copayment of $40 \%$. Workers with income between $€ 18,000$ and $€ 100,000$ form group TSI 004 and they have a pharmaceutical co-payment of $50 \%$. Workers and pensioners with income above $€ 100,000$ form group TSI 005 and they have a pharmaceutical co-payment of $60 \%$ (and for pensioners a monthly limit of $€ 60$ ).

The prescription of antibiotics of 2020 was compared to the prescription of 2019. Furthermore, the DID prescribed in February, March, April and May 2020 were compared with the prescription of the same months in 2019 using the Chisquare test with a significance level of 0.05 . The analyses were performed using IBM SPSS Statistics 24 software. $^{23}$

\section{Results}

\section{Antibiotic Prescription by Active Principle}

Figure 1 shows the total prescription of antibiotics and the six active principles, which were most prescribed. The six 


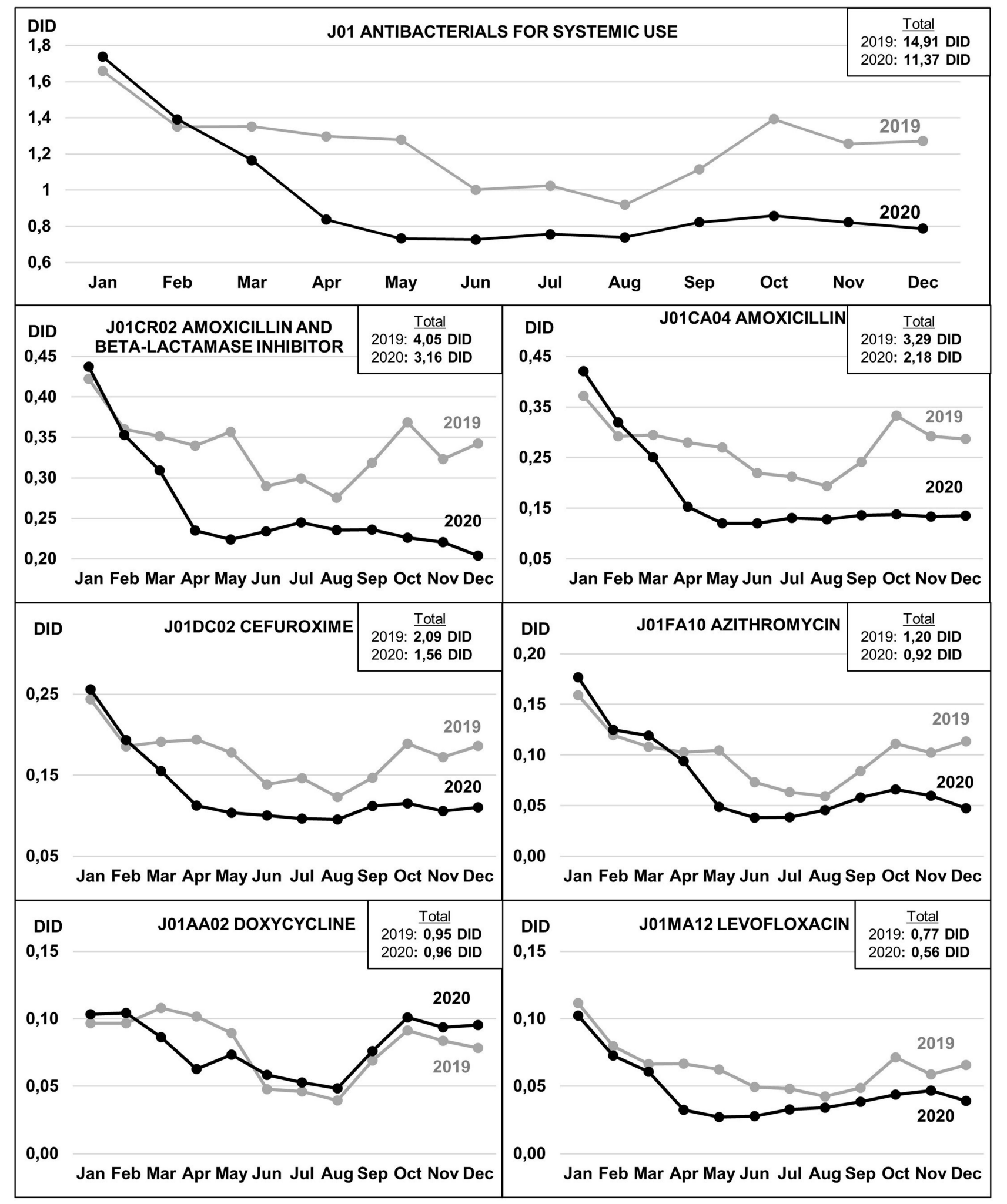

Figure I Antibiotic prescription by J0I classification in La Rioja (2019 and 2020).

active principles account for $82 \%$ of total antibiotic prescriptions, 12.35 of 14.91 DID (the total prescription in 2019) and 9.33 of 11.37 DID (the total prescription in
2020). In 2020, the total antibiotics prescribed were significantly lower than the total in 2019 , with significant savings of -3.54 DID $(-23.73 \%$; $=0.029),-55,131$ 
recipes $(-28.11 \%$; $\mathrm{p}=0.017),-63,234$ packs $(-28.65 \%$; $\mathrm{p}=0.015),-438,090$ euros $(-27.52 \% ; \mathrm{p}=0.025)$.

The DID prescribed were higher in January 2020 than in the same month in 2019 in total antibiotics (4.58\%), amoxicillin and beta-lactamase inhibitor (3.65\%), amoxicillin (13.13\%), cefuroxime (4.96\%), azithromycin (11.18\%) and doxycycline (7.06\%).

The DID prescribed were higher in February 2020 than in the same month in 2019 in total antibiotics (3\%), amoxicillin $(9.26 \%)$, cefuroxime $(4.15 \%)$, azithromycin $(4.62 \%)$ and doxycycline (8\%).

From March to December, the DID prescribed in 2020 were lower than in the same period in 2019 in total antibiotics $(-30.73 \%)$, amoxicillin and beta-lactamase inhibitor $(-27.47 \%)$, amoxicillin $(-44.96 \%)$, cefuroxime $(-33.46 \%)$ and azithromycin $(-33.32 \%)$. In the case of levofloxacin, the total DID prescribed in all the months of 2020 ( 0.56 DID) were $27.63 \%$ lower than in 2019 (0.77 DID). All the previous differences were statistically significant $(p<0.05)$. Azithromycin was the only active principle that presented a higher prescription (10.11\%) in March 2020 (0.119 DID) than the same month in 2019 (0.108 DID).

\section{Antibiotic Prescription by Basic Health Zone}

Figure 2 shows antibiotic prescription by BHZ in 2019 and 2020. The prescription of DID was lower in 2020 than in 2019 in all zones, which implies significant variations $(\mathrm{p}<0.05)$ from $-9.5 \%$ (Camero Viejo) to $-32.7 \%$ (Logroño ZBS 16). The prescription in nursing homes in 2019 was $24.51 \mathrm{DID}$, which implies a significant variation $(p<0.05)$ of $-29.17 \%$ compared to the 17.36 DID prescribed in 2020.

In February 2020, the prescription of antibiotics was higher than the same month in 2019 in 15 of the 21 basic health zones. The biggest differences were found in Camero Nuevo (1.19 DID in 2019 and 2.81 DID in 2020, which implies a significant variation of $136.13 \%$ ), nursing homes (1.64 DID in 2019 and 2.81 DID in 2020, significant variation of $71.34 \%)$ and Camero Viejo (0.93 DID and 1.33 DID, significant variation of $43.01 \%$ ).

In March 2020, the prescription of antibiotics was higher than the same month in 2019 in 4 of the 21 basic health zones. The biggest differences were found in Logroño ZBS 20 (1.03 DID in 2019 and 0.69 DID in 2020 , which implies a significant variation of $-33 \%$ ) and in nursing homes (1.92 DID in 2019 and 1.45 DID in 2020, significant variation of $-24.47 \%$ ).

In April 2020, the prescription of antibiotics was lower than the same month in 2019 in all basic health zones, with an average decrease of $-31.5 \%$ DID. In May 2020, the prescription of antibiotics was lower than the same month in 2019 in all basic health zones, with an average decrease of $-35.5 \%$ DID.

\section{Antibiotic Prescription by Age Group and Sex}

Figure 3 shows antibiotic prescription by age group and sex, comparing the total year (2019 and 2020) and February, March, April and May 2019 with the same

\begin{tabular}{|c|c|c|c|c|c|c|c|c|c|c|c|}
\hline $\mathrm{BHZ}$ & POP. & YEAR & DID & $\mathrm{BHZ}$ & POP. & YEAR & DID & $\mathrm{BHZ}$ & POP. & YEAR & DID \\
\hline \multirow{2}{*}{ CALAHORRA } & \multirow{2}{*}{34.121} & 2019 & 15,31 & \multirow{2}{*}{ ARNEDO } & \multirow{2}{*}{18.336} & 2019 & 15,81 & \multirow{2}{*}{ LOGROÑO (BHZ13) } & \multirow{2}{*}{10.509} & 2019 & 15,41 \\
\hline & & 2020 & 11,50 & & & 2020 & 12,68 & & & 2020 & 11,94 \\
\hline \multirow{2}{*}{ LOGROÑO (BHZ14) } & \multirow{2}{*}{27.495} & 2019 & 16,47 & \multirow{2}{*}{ HARO } & \multirow{2}{*}{18.216} & 2019 & 18,96 & \multirow{2}{*}{ NAVARRETE } & \multirow{2}{*}{10.319} & 2019 & 19,35 \\
\hline & & 2020 & 12,77 & & & 2020 & 14,82 & & & 2020 & 15,05 \\
\hline \multirow{2}{*}{ LOGROÑO (BHZ15) } & \multirow{2}{*}{27.043} & 2019 & 16,11 & \multirow{2}{*}{ ALFARO } & \multirow{2}{*}{16.129} & 2019 & 19,10 & \multirow{2}{*}{$\begin{array}{l}\text { MURILLO DE RÍO } \\
\text { LEZA }\end{array}$} & \multirow{2}{*}{5.518} & 2019 & 19,33 \\
\hline & & 2020 & 12,52 & & & 2020 & 14,70 & & & 2020 & 16,18 \\
\hline \multirow{2}{*}{ LOGROÑO (BHZ18) } & \multirow{2}{*}{24.759} & 2019 & 12,04 & \multirow{2}{*}{ NÁJERA } & \multirow{2}{*}{15.780} & 2019 & 19,61 & \multirow{2}{*}{$\begin{array}{l}\text { CERVERA DE RIO } \\
\text { ALHAMA }\end{array}$} & \multirow{2}{*}{3.708} & 2019 & 22,28 \\
\hline & & 2020 & 9,29 & & & 2020 & 15,37 & & & 2020 & 18,16 \\
\hline \multirow{2}{*}{ ALBERITE } & \multirow{2}{*}{21.186} & 2019 & 15,34 & \multirow{2}{*}{ LOGROÑO (BHZ20) } & \multirow{2}{*}{15.207} & 2019 & 11,13 & \multirow{2}{*}{ NURSING HOMES } & \multirow{2}{*}{1.394} & 2019 & 24,51 \\
\hline & & 2020 & 12,06 & & & 2020 & 7,50 & & & 2020 & 17,36 \\
\hline \multirow{2}{*}{ LOGROÑO (BHZ17) } & \multirow{2}{*}{20.834} & 2019 & 13,68 & \multirow{2}{*}{ LOGROÑO (BHZ16) } & \multirow{2}{*}{12.284} & 2019 & 18,93 & \multirow{2}{*}{ CAMERO NUEVO } & \multirow{2}{*}{1.000} & 2019 & 21,32 \\
\hline & & 2020 & 10,89 & & & 2020 & 12,74 & & & 2020 & 19,30 \\
\hline LOGROÑO (BHZ19) & 19333 & 2019 & 10,67 & SANTO DOMINGO & 10.534 & 2019 & 17,51 & CAMERO VIEJO & 269 & 2019 & 20,35 \\
\hline (2) & 10.000 & 2020 & 8,37 & DE LA CALZADA & 0.007 & 2020 & 13,06 & 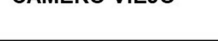 & 200 & 2020 & 16,17 \\
\hline
\end{tabular}

Figure 2 Antibiotic prescription by basic health zone in La Rioja (2019 and 2020). 


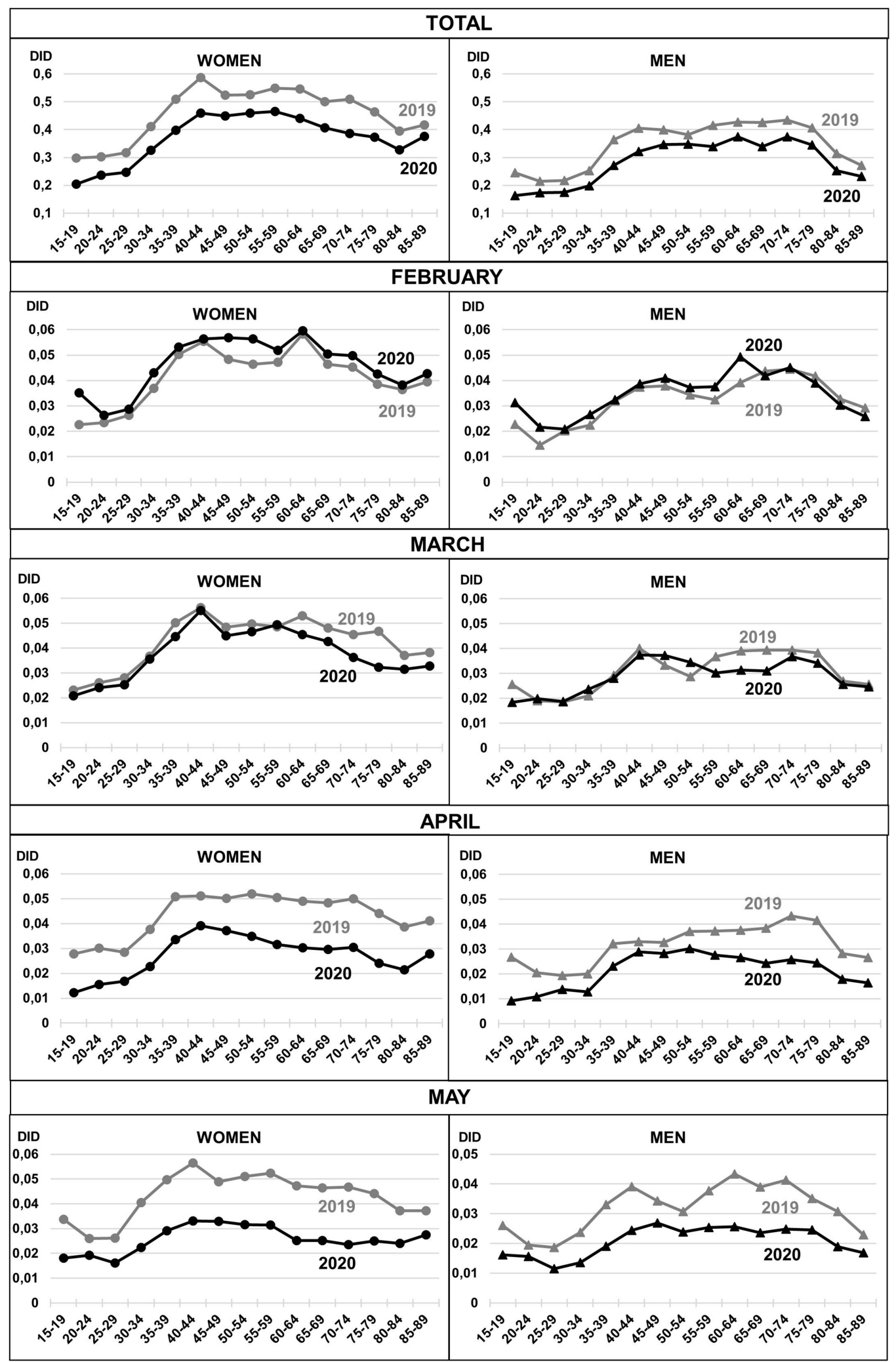

Figure 3 Antibiotic prescription by age group and sex (2019 and 2020). 
months in 2020. The total prescription in 2020 was lower than in 2019 , with a significant reduction of $-22.14 \%$ in women and $-24.33 \%$ in men.

In February 2020, the prescription was higher in women of all age groups and men (15 to 65 years) but no significant differences were found. In March 2020, the prescription was lower than in the same month in 2019, but only significant differences were found in women (60 to 89 years old). In April and May 2020, the prescription was lower than in the same months in 2019, with a significant reduction in May $(-36.24 \%$ in women and $-31.62 \%$ in men) and in April $(-39.45 \%$ in women and $-34.08 \%$ in men).

\section{Antibiotic Prescription by Co-Payment Rate Determined by Level of Income}

Figure 4 shows antibiotic prescription by type of copayment, which is determined by the income level of the patient. The prescription was lower in all co-payment groups in 2020 than in $2019(-23.98 \%$ in TSI 002 , $-27.59 \%$ in TSI 003 and $-15.80 \%$ in TSI 004$)$.

In February and March 2020, the prescription was lower than the same months in 2019 in TSI 002 and TSI 003 and it was higher in TSI 004, but any significant differences were found. In April and May 2020, the prescription was lower than the same months in 2019 in all income groups with significant differences in TSI 002 $(-37.29 \%$ in April and $-42.67 \%$ in May) and TSI 003 $(-37.11 \%$ in April and $-46.34 \%$ in May).

\section{Discussion}

Studies are reporting the widespread appearance of AMR due to the high use of antibiotics in COVID-19 patients, even when these drugs do not fight against viral infections. ${ }^{8}$ In hospital care, extensive use of broadspectrum antibiotics in COVID-19 patients was found in an international survey performed in 82 hospitals from 23 countries. ${ }^{9}$ In the Spanish Health System, a significant increase in the consumption of antibiotics in hospitals was registered in the period before the pandemic. ${ }^{10}$ In primary care, in order to prevent population's exposure to viruses, several national health systems ${ }^{11-15}$ opted to implement teleconsultations, in which patients communicate with the general practitioner (GP) through telephone or other technological means. It was found that practitioners had difficulties distinguishing the pathogen from the infection ${ }^{16}$ and that more antibiotics were prescribed in online consultations than in usual consultations. ${ }^{17}$

The variation in the prescription of antibiotics was analyzed in a regional health system during the months in which protection measures against COVID-19 were implemented. In 2020, the total of antibiotics prescribed in La Rioja was significantly lower than the total in 2019, which significantly savings of -3.54 DID (-23.73\%; $\mathrm{p}=0.029),-55,131$ recipes $(-28.11 \% ; \mathrm{p}=0.017),-63,234$ packs $(-28.65 \%$; $\mathrm{p}=0.015),-438,090$ euros $(-27.52 \%$; $\mathrm{p}=0.025)$.

The greatest reduction in the prescription of antibiotics in La Rioja occurred between the months of March to December, with a drop of $-30.73 \%$ of the total DID prescribed. However, in January 2020, the DID prescribed were $4.58 \%$ higher than in the same month in 2019 and in February 2020, a 3\% higher than in the same month in 2019. Between December 2019 and February 2020, a large number of deaths were reported worldwide from pneumonia of unknown origin, which were later suspected to be caused by COVID-19, which in turn could imply an increase in antibiotic use. ${ }^{24}$ The prescription was significantly higher in February 2020 than in the same month in 2019 in nursing homes (71.34\%), where the pandemic had severe effects. ${ }^{25}$

A risk factor that causes complications in patients with COVID-19 is an impaired immune system due to excessive use of antibiotics, which could explain the high prevalence in nursing homes. ${ }^{26}$ Advanced age and the existence of comorbidities are conditions that lead to a high risk of hospitalization and mortality rate due to COVID-19 infection. ${ }^{27}$ In addition to clinical determinants, it has been detected that the incidence of COVID19 is related to economic variables and it increases as the patient's income level or neighbourhoods wealth decreases. ${ }^{28-30}$ No significant differences were found by age groups in the DID prescribed in February 2020 compared to the same month 2019, neither in women nor in men. In March 2020, the entry into force of the home lockdown of the entire population began. In this month 2020 , the prescription was lower $(-13.71 \%)$ than in the same month in 2019, except for the middle-income group (TSI 004), in which the prescription was higher (9.67\%). Lockdown has been reported to help reduce the inappropriate use of antibiotics. ${ }^{26}$ Azithromycin was the only active principle that increased its prescription in March 2020 compared to the same month in 2019 $(10.11 \%)$. It is necessary to remember that it was the first 


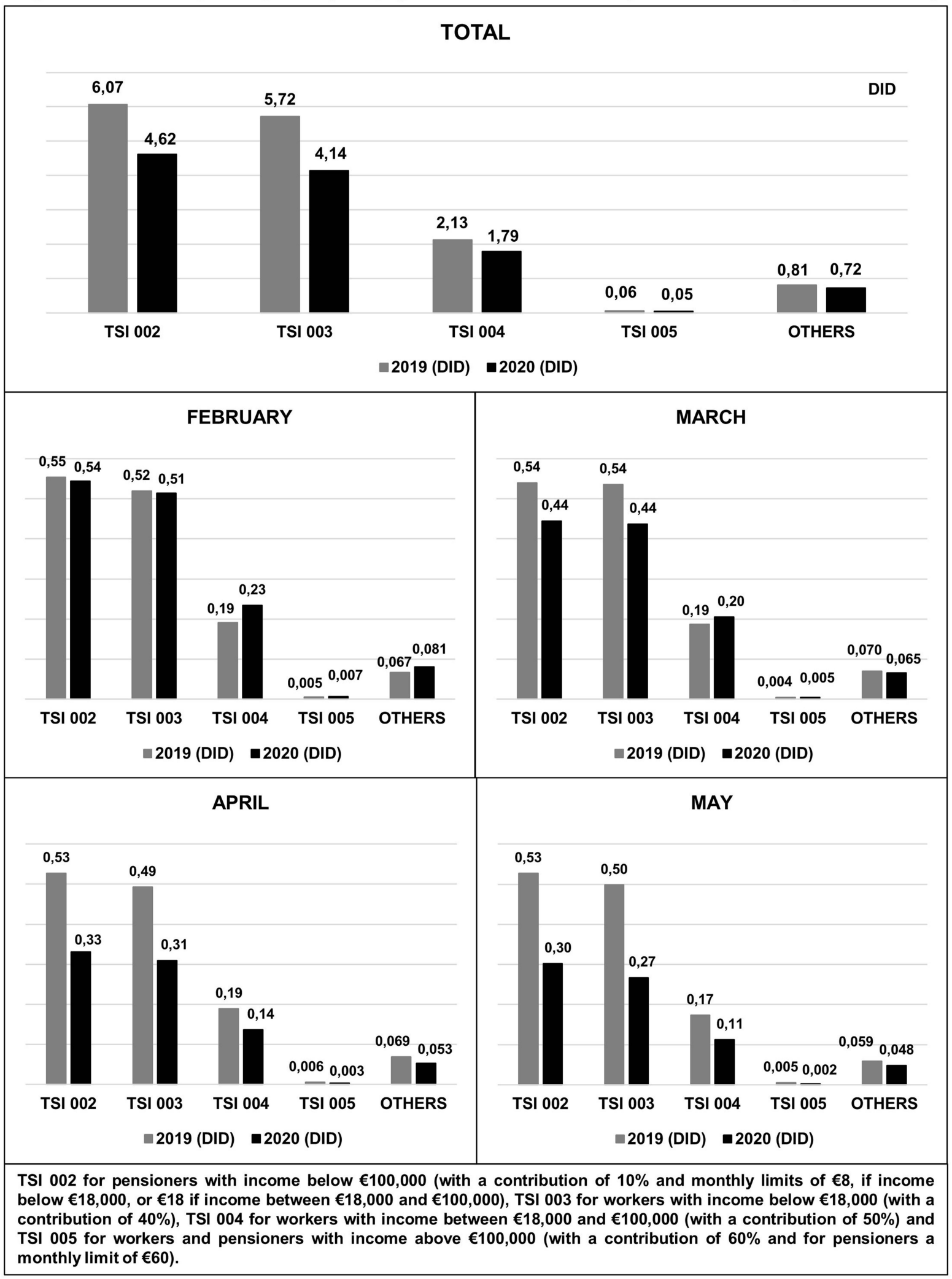

Figure 4 Antibiotic prescription by co-payment rate determined by level of income (2019 and 2020). 
treatment option tested against COVID-19 in the clinical practice. ${ }^{3}$ In April and May 2020, the prescription was significantly lower than in 2019 in all age groups, both in women and men as well as all income-level groups. The main difference when comparing the amount prescribed in 2019 and 2020 was found in the month of May $(-42.64 \%)$.

The national consumption of antibiotics registered a decrease of $21 \%$ in primary care between January and July 2020 compared to the same period in $2019 .^{26}$ In the present study, looking at the same periods, the decrease at the regional level was $18 \%$. Also, it was reported that the consumption of antibiotics in primary care decreased by $40 \%$ between April and May 2020 compared to the same period in 2019 due to the decrease in activity in health centres during confinement. ${ }^{26}$ In the present study, this reduction was $39.03 \%$, mainly in levofloxacin prescription $(-53.81 \%)$, the youngest group ( $-50.64 \%$ women $15-19$ years and $-52.03 \%$ men same age group) and the high-income group (TSI 005) $(-49.83 \%)$. Furthermore, there was a significant rise in the consumption of antibiotics in hospitals during the first months of the pandemic, with an increase of $40 \%$ in the month of March 2020 compared to the same month in 2019. The diagnostic uncertainty at the onset of the pandemic and the prescription of antibiotics in COVID-19 patients with bacterial coinfection or superinfection enhanced this increase. ${ }^{26}$

In a previous study, it was concluded that other economic and clinical measures, such as an increase in co-payment rates and the implementation of awareness and rational antibiotic use campaigns, have also reduced antibiotics consumption but at a lower rate (around an $-8 \%$ and a $-5 \%$, respectively). ${ }^{27}$ However, it was reported that the effect of co-payment disappeared over time and could not be implemented periodically. Also, co-payment reduces the intake of all medicines due to an increase in the price borne by patients. ${ }^{28,29}$ Also, awareness campaigns do not always achieve the desired effect on society. ${ }^{27}$ However, personal protection measures could be maintained over time, especially in winter months and nursing homes (with traditionally more antibiotics' prescription) in order to reduce inappropriate antibiotic consumption, which directly affects resistance rates.

A limitation of this study is that it only includes a series of dispensations of antibacterial for systematic use (group J01 of the ATC classification). If we focus on the total therapeutic groups in the ATC classification, data provided by the Ministry of Health $^{30}$ (note that pediatric information is included), the total number of official recipes dispensed in 2020 in La Rioja decreased by $-0.65 \%$ and total expenditure increased by
$0.36 \%$, compared to 2019 . In Spain, the number of recipes increased by $0.82 \%$ and total expenditure by $2.63 \%$ compared to 2019. It is observed that these variations are lower, even positive, if we compare them with the results of this study ( $-28.11 \%$ recipes and $-27.52 \%$ euros in 2020 compared to 2019). This may be due to the fact that total prescriptions also include medications for chronic diseases, such as antidiabetics (ATC-A10), antithrombotics (ATC-B01) and agents against obstructive conditions of the respiratory tract (ATC-R03). However, the current information disaggregated by ATC therapeutic group is not available as it is published two years later in the Ministry of Health's statistics. So that, the last year available was $2018 .^{31}$ Also, the paediatric population was not included in this study as the use of DID as unit of utilization is established for adult consumption, following WHO methodology. ${ }^{21}$ Finally, due to the difficulty of obtaining data on personal protection measures (the frequency of individual proper use of the mask, the maintenance of social distance or the increase in hygiene), an ecological study has not been performed.

\section{Conclusions}

The prescription of antibiotics in 2020 (period of implementation of the COVID-19 protection measures) was significantly lower $(-23.73 \%)$ than in the previous year. This study has analysed how a series of antibiotics prescribed in primary care had behaved during the months of implementation of the COVID-19 protection measures in a disaggregated way, by month, active principle, age, sex and income level of the patient. Despite being difficult to measure the effect of personal protection measures, that is, to quantify individual use of masks, compliance with social distance or even increased hygiene, these measures could be an additional reason to the lockdown that began in March 2020, in order to more comprehensibly explain the reduction in the dispensing of antibiotics.

\section{Highlights}

- Antibiotic resistance (AMR) was the main health threat before the coronavirus-19 (COVID-19) pandemic. This study analyzes the prescription of antibiotics during the implementation of COVID-19 personal protection measures in primary care in a Spanish region.

- In 2020, the prescription of antibiotics (11.37 DID) was significantly lower (-23.73\%) than in 2019 (14.91 DID).

- Personal protection measures against COVID-19 transmission coincide in time with the greatest reduction of antibiotic prescription. 


\section{Ethics Approval}

This is not applicable as the analysis uses a series of information from aggregated data.

\section{Acknowledgments}

The authors thank Professors Carmen Torres Manrique and Roberto Rodríguez Ibeas for their comments and suggestions in the review of the results. The authors thank the Head of the Health Department of the Government of La Rioja for its support and collaboration in this study.

\section{Author Contributions}

All authors made a significant contribution to the work reported, whether that is in the conception, study design, execution, acquisition of data, analysis and interpretation, or in all these areas; took part in drafting, revising or critically reviewing the article; gave final approval of the version to be published; have agreed on the journal to which the article has been submitted; and agree to be accountable for all aspects of the work.

\section{Funding}

This paper was funded by a predoctoral contract FPI-CAR 2018.

\section{Disclosure}

The authors have no relevant affiliations or financial involvement with any organization or entity with a financial interest in or financial conflict with the subject matter or materials discussed in the manuscript. This includes employment, consultancies, honoraria, stock ownership or options, expert testimony, grants or patents received or pending, or royalties.

\section{References}

1. Medina MT, Moncada SS. Hydroxychloroquine/chloroquine as a treatment choice or prophylaxis for Covid-19 at the primary care level in developing countries: a Primum non Nocere dilemma. J Neurol Sci. 2020;415:116972. doi:10.1016/j.jns.2020.116972

2. Beigel JH, Tomashek KM, Dodd LE, et al. Remdesivir for the treatment of Covid-19 - final report. $N$ Engl J Med. 2020;383 (19):1813-1826. doi:10.1056/NEJMoa2007764

3. Oldenburg CE, Doan T. Azithromycin for severe COVID-19. Lancet. 2020;396(10256):936-937. doi:10.1016/S0140-6736(20) 31863-8

4. Furtado RHM, Berwanger O, Fonseca HA, et al. Azithromycin in addition to standard of care versus standard of care alone in the treatment of patients admitted to the hospital with severe COVID-19 in Brazil (COALITION II): a randomised clinical trial. Lancet. 2020;396(10256):959-967. doi:10.1016/S0140-6736(20)31862-6
5. Fiolet T, Guihur A, Rebeaud ME, Mulot M, Peiffer-Smadja N, Mahamat-Saleh Y. Effect of hydroxychloroquine with or without azithromycin on the mortality of coronavirus disease 2019 (COVID-19) patients: a systematic review and meta-analysis. Clin Microbiol Infect. 2021;27(1):19-27. doi:10.1016/j.cmi.2020.08.022

6. Gonzalez-Zorn B. Antibiotic use in the COVID-19 crisis in Spain. Clin Microbiol Infect. 2021;27(4):646-647. doi:10.1016/j.cmi.2020.09.055

7. Antimicrobial resistance. European centre for disease prevention and control; 12 de marzo de 2021. Disponible en: https://www.ecdc. europa.eu/en/antimicrobial-resistance. Accessed November 7, 2021.

8. Coronavirus disease (COVID-19): Herd immunity, lockdowns and COVID-19 [Internet]. World Health Organization; 2020 [citado 26 de enero de 2021]. Disponible en: https://www.who. int/news-room/q-A-detail/herd-immunity-lockdowns-and-covid -19. Accessed November 7, 2021.

9. State official newsletter. Royal Decree 463/2020, of March 14, which declares the state of alarm for the management of the health crisis situation caused by COVID-19. [Internet]. 67. Sec:25390-25400. Disponible en: https://www.boe.es/boe/dias/2020/03/14/pdfs/BOEA-2020-3692.pdf. Accessed November 7, 2021.

10. State official newsletter. Order SND / 422/2020, of May 19, which regulates the conditions for the mandatory use of a mask during the health crisis caused by COVID-19. [Internet]; May 20, 2020:33600-33602. Disponible en: https:/www.boe.es/buscar/doc.php?id=BOE-A-20205142. Accessed November 7, 2021.

11. COVID-19 early detection, surveillance and control strategy [Internet]. Ministerio de Sanidad. Gobierno de España; 2020 [citado 25 de enero de 2021]. Disponible en: https://www.mscbs.gob.es/pro fesionales/saludPublica/ccayes/alertasActual/nCov/documentos/ COVID19_Estrategia_vigilancia_y_control_e_indicadores.pdf. Accessed November 7, 2021.

12. Romero L, Pao LZ, Clark H, et al. Health center testing for SARSCoV-2 during the COVID-19 pandemic - United States, June 5October 2, 2020. Morb Mortal Wkly Rep. 2021;69(50):1895-1901. doi:10.15585/mmwr.mm6950a3

13. Wolters F, van de Bovenkamp J, van den Bosch B, et al. Multi-center evaluation of cepheid xpert巴 xpress SARS-CoV-2 point-of-care test during the SARS-CoV-2 pandemic. J Clin Virol. 2020;128:104426. doi:10.1016/j.jcv.2020.104426

14. de Wolff T, Pflüger D, Rehme M, Heuer J, Bittner M-I. Evaluation of pool-based testing approaches to enable population-wide screening for COVID-19. PLoS One. 2021;15:e243692. doi:10.1371/journal. pone. 0243692

15. Gagliotti C, Buttazzi R, Ricchizzi E, Di Mario S, Tedeschi S, Moro ML. Community use of antibiotics during the COVID-19 lockdown. Infect Dis. 2021;53(2):142-144. doi:10.1080/2374423 5.2020 .1834139

16. Collaborating Centre for Drug Statistics Methodology. ATC/DDD Index. World Health Organization [Internet]; 2020 [citado 28 de enero de 2021]. Disponible en: https://www.whocc.no/atc_ddd index/?code $=$ J01\&showdescription=no. Accessed November 7, 2021.

17. State official newsletter. Royal Decree-Law 16/2012, of April 20, on urgent measures to guarantee the sustainability of the National Health System and improve the quality and safety of its services. BOE núm. 98; April 24, 2012.

18. Statistics National Institute. Population Figures. Provisional as of July 1, 2020; 25 de marzo de 2021. Disponible en: https://www.ine. es/dyngs/INEbase/es/operacion.htm?c=Estadistica_C\&cid= 1254736176951\&menu=ultiDatos\&idp=1254735572981. Accessed November 7, 2021.

19. Budgets of the Autonomous Communities: Health. Expansión; 25 de marzo de 2021. Disponible en: https://datosmacro.expansion.com/ estado/presupuestos/espana-comunidades-autonomas?sc=PR-G-F-31. Accessed November 7, 2021. 
20. Rioja Health. Basic Health Zones; 25 de marzo de 2021. Disponible en: https://www.riojasalud.es/ciudadanos/informacion/libre-eleccionsanitaria/atencion-primaria.

21. Organización Mundial de la Salud. Defined daily dose (DDD). Definition and general considerations [Internet]; [citado 22 de octubre de 2021]. Disponible en: https:/www.who.int/tools/atc-ddd-toolkit /about-ddd. Accessed November 7, 2021.

22. Pediatricians attend up to 14 years of age and, for now, they do not want more; [citado 22 de octubre de 2021]. Disponible en: https:// www.redaccionmedica.com/secciones/pediatria/los-pediatrasatienden-hasta-los-14-anos-y-de-momento-no-quieren-mas-3026. Accessed November 7, 2021.

23. IBM Corp. IBM SPSS Statistics for Windows. Armonk, NY: IBM Corp; 2016.

24. Burgos Rincón F, Martínez Llorens J, Cordovilla Pérez R. Impact of the COVID-19 pandemic on lung function laboratories: considerations for "Today" and the "Day After". Arch Bronconeumol. 2020;56 (10):611-612. doi:10.1016/j.arbres.2020.07.001

25. Grabowski DC, Mor V. Nursing home care in crisis in the wake of COVID-19. JAMA. 2020;324(1):23-24. doi:10.1001/jama.2020.8524

26. National Plan against Antibiotic Resistance (PRAN). EAAD 2020 Conference: Antibiotic consumption in Spain recovers its pre-pandemic downward trend; 18 de noviembre de 2020. Disponible en: https://resis tenciaantibioticos.es/en/node/578. Accessed November 7, 2021.
27. Rojas García P, Antoñanzas Villar F. Effects of economic and health policies on the consumption of antibiotics in a Spanish region. Expert Rev Pharmacoecon Outcomes Res. 2020;20(4):379-386. doi:10.1080/14737167.2019.1647105

28. Antoñanzas Villar F, Rodríguez-Ibeas R, Juárez-Castelló CA, Lorente Antoñanzas MR. Impact of the Royal Decree-Law 16/2012 on the Number of Prescriptions and Pharmaceutical Expenditures. Rev Esp Salud Pública. 2014;88(2):233-249. doi:10.4321/S113557272014000200006

29. Puig-Junoy J, Rodríguez-Feijóo S, López-Valcárcel BG. Impact of the Pharmaceutical Copayment Reform on the Use of Antidiabetics, Antithrombotics and Drugs for Chronic Airflow Obstructions. Spain. Rev Esp Salud Pública. 2017;90:15.

30. Ministry of Health. Prescription billing information; 26 de marzo de 2021. Disponible en: https://www.mscbs.gob.es/profesionales/farmacia/ datos/diciembre2020.htm. Accessed November 7, 2021.

31. Ministries of Health. Pharmaceutical Benefit in the National Health System Annual Report of the National Health System 2018; 2020. Disponible en: https:/www.mscbs.gob.es/estadEstudios/estadisticas/ sisInfSanSNS/tablasEstadisticas/InfAnualSNS2018/Cap.7_Farmacia. pdf. Accessed November 7, 2021.
ClinicoEconomics and Outcomes Research

\section{Publish your work in this journal}

ClinicoEconomics and Outcomes Research is an international, peerreviewed open-access journal focusing on Health Technology Assessment, Pharmacoeconomics and Outcomes Research in the areas of diagnosis, medical devices, and clinical, surgical and pharmacological intervention. The economic impact of health policy and health systems

\section{Dovepress}

organization also constitute important areas of coverage. The manuscript management system is completely online and includes a very quick and fair peer-review system, which is all easy to use. Visit http://www.dovepress.com/testimonials.php to read real quotes from published authors. 